\title{
Mechanical and damage similarities of adobe blocks reinforced with natural and industrial fibres
}

\author{
José Concha-Riedel ${ }^{1}$, Federico C. Antico ${ }^{2}$, \\ Gerardo Araya-Letelier ${ }^{3}$
}

\author{
${ }^{1}$ Universidad Adolfo Ibáñez, Facultad de Ingeniería y Ciencias, Diagonal las Torres 2700, Peñalolén, Región Metropoli- \\ tana, Chile. \\ ${ }^{2}$ Universidad Adolfo Ibáñez, Facultad de Ingeniería y Ciencias, Avenida Padre Hurtado 750, Viña del Mar, Región de \\ Valparaíso, Chile. \\ ${ }^{3}$ Pontificia Universidad Católica de Chile, Escuela de Construcción Civil, Avenida Vicuña Mackenna 4860, Macul, \\ Región Metropolitana, Chile. \\ e-mail: jose.concha@uai.cl,federico.antico@uai.cl,gerardo.araya@uc.cl
}

\begin{abstract}
Adobe is an earthen-based material that consists of the use of a clayey soil and, most of the times, straw fibres to manufacture blocks that are afterwards sundried. This study reviews the use of three types of fibres: vegetal, industrial and animal, for the manufacture of adobe blocks. Overall, all the fibres increase at least one order of magnitude the impact strength of plain adobe blocks and reduced the shrinkage cracking of adobe plasters in at least $50 \%$ with respect to plain adobe. Compressive and flexural strength average values were not increased nor decreased by the addition of fibres. The intrinsic variability of the mechanical properties of plain adobe persists with any of the fibres tested in this study. Based on the findings of this study, we recommend using jute fibres with a dosage of $0.5 \%$ and a length of $30 \mathrm{~mm}$.
\end{abstract}

Keywords: Crack control, natural fibres, industrial fibres, adobe blocks, impact strength

\section{INTRODUCTION}

An increasing interest in climate change has emerged in recent years due to the alarming sea-level rise and the increment of the surface temperature of the oceans $[1,2]$. In that regard, the materials commonly used in the construction sector are responsible for approximately $23 \%$ of the carbon dioxide emissions [3], being steel and cement the construction materials that represent the largest percentages. On the other hand, the increasing demand for housing is also one of the current concerns of global governments and, therefore, it is worth noticing that still, approximately $30 \%$ of the global population lives in earthen housing [4]. Estimations predict that by 2030 the global population will increase from 7.3 (2015) to 8.5 billion [5] and, consequently, new and more sustainable construction solutions must be studied, developed and implemented to address mitigation of climate change [6].

Earthen buildings have existed as one of the oldest housing techniques developed by humans, including some earthen constructions lasting until today that are living testaments of the durability and performance of earthen materials [7]. Typically, earthen constructions are found in regions such as North Africa and the Middle East, where the first civilizations of humans were established. However, traces of earthen housing has been also found in Asia, Oceania and America [8]. Earthen buildings can be developed using different construction techniques, which are generally related to the construction location. Adobe construction, one of the earthen construction techniques, consists of masonry construction made of manually compacted earthen blocks. The dimensions of the blocks vary between different locations. In particular, the manufacturing process of adobe blocks consists of a mix made of clayey soil that is manually combined with water and, most of the times, randomly distributed straw fibres. After the mixing is completed, the adobe blocks are cast on the ground and let sundry for two to four weeks [9-11].

Several studies have extensively addressed the effect of vegetal fibres on the properties of adobe blocks [12-14]. One of those studies made by LABOREL-PRÉNERON et al. [12] reviewed several 
investigations addressing the mechanical (compressive and flexural strength), durability (resistance to water) and physical (density, water absorption and drying shrinkage) of vegetal fibre-reinforced earthen material. On the other hand, industrial fibres, commonly used as fibre reinforcement in cement-based material, have not been extensively studied on adobe blocks. BININCI et al. [15]observed the effect on the compressive strength of earthen bricks reinforced with plastic and polystyrene fibres, and compare it to earthen bricks reinforced with straw fibres. Plastic fibres reinforced adobes had an average compressive strength response of $17 \%$ higher than straw fibre reinforced ones. While polystyrene reinforced adobes compressive strength was $31 \%$ lower than straw fibre bricks. In terms of animal fibres, this type of natural fibres has only been studied, to the authors best knowledge, by two researchers ARAYA-LETELIER et al. $[16,17]$ and AYMERICH et al. [18]. Araya-LETELIER et al. [16] addressed the influence of chicken feather fibres on the mechanical and crack control performance of adobe mixes. Flexural and compressive strength proven to increase negligible, but crack control was reduced up to 99\%. ARAYA-LETELIER et al. [17] also observed the effect of pig-hair fibre on the compressive and flexural strength, as well as the post-fracture behaviour of these fibre-reinforced blocks. Their results show that pig-hair fibres improve up to 47 times the energy absorption of reinforced adobe compared to plain adobe blocks. Aymerich et al. studied the effect of sheep wool on the fracture properties of adobe blocks. Overall, wool fibres improve energy absorption of adobe blocks, however, no other mechanical properties were evaluated. In general, studies have investigated the mechanical properties of reinforced adobe blocks, but these studies have not compared thoroughly the effect of different fibre types, including both natural and synthetic fibres, on the damage behaviour of adobe blocks, which is the novelty of this paper. The objective of this work is to present and compare the effect of vegetal (jute), animal (pig-hair) and synthetic (micro polypropylene) fibres on the mechanical and fracture properties of adobe blocks.

\section{MATERIALS AND TEST METHODS}

\subsection{Soil}

All the specimens of this study used a clayey soil from the city of Santiago, Chile. Sieve analysis and Atterberg limits test were performed following the standards ASTM D7928 [19] and ASTM D4318 [20]. Figure 1 presents the sieve analysis of the soil used for this study (solid line), as well as the sieve analysis from other authors to use them as a reference [21-24]. As can be seen, the particle size distribution of soil used in our study is within the particle size distribution of the ones used by other researchers. Atterberg limits are presented in Table1, and the soil classification following the Unified Soil Classification System is well-graded clayey sand [25].

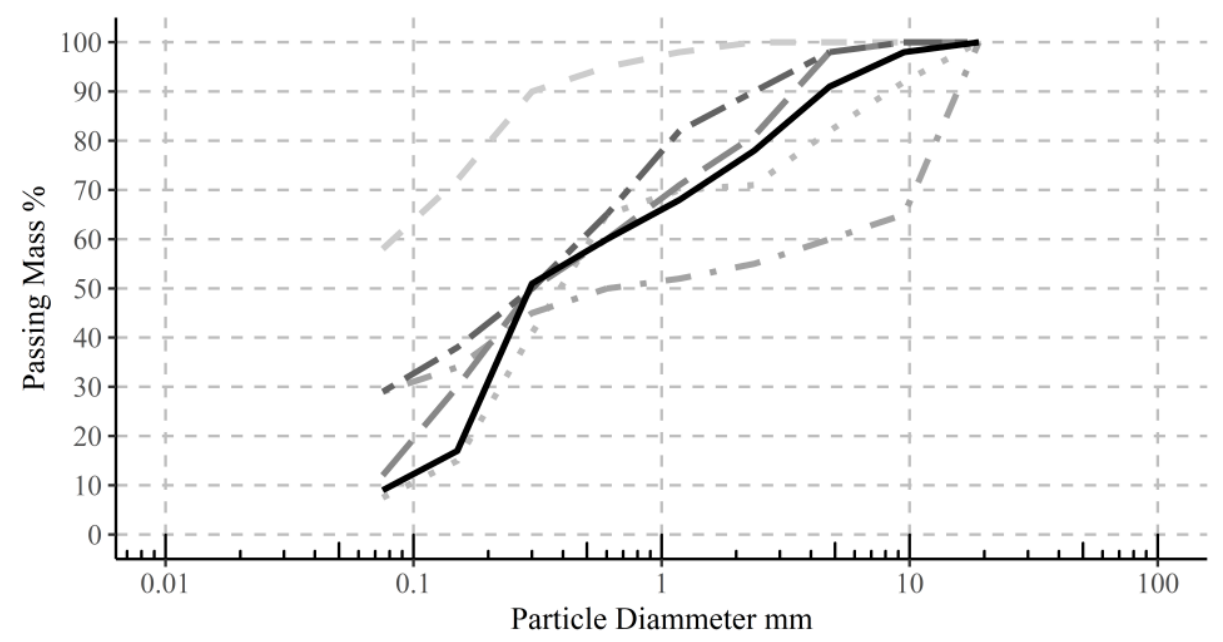

$$
\begin{aligned}
& \text { Duarte et al. (1) [22] " - Fabbri et al. [24] - - Santos et al. [23] } \\
& \text { Duarte et al. (2) [22] — Niño Villamizar et al. [21] — This Study }
\end{aligned}
$$

Figure 1: Gradation curves of this study (solid line) and worked by NIÑO VILLAMIZAR et al. [21] (long-dashed line), DUARTE et al. [22] (dotted and dashed lines), SANTOS et al. [23] (small-long dashed line) and FABBRI et al. [24] (dot-dashed line) 
Table 1: Physical properties of soil to manufacture adobe for this work

\begin{tabular}{c|c|c|c|c}
\hline PLASTIC LIMIT \% & LIQUID LIMIT \% & $\begin{array}{c}\text { PLASTICITY } \\
\text { INDEX \% }\end{array}$ & DENSITY KG/M3 & $\begin{array}{c}\text { SOIL CLASSIFI- } \\
\text { CATION }\end{array}$ \\
\hline 17.4 & 29.1 & 11.7 & 2507 & SW-SC \\
\hline
\end{tabular}

\subsection{Fibres}

Three different fibres were used in this study: jute, micro polypropylene and pig-hair (Figure 2). The diameter of jute-fibres varies between 0.102 and $0.203 \mathrm{~mm}$. Micro polypropylene fibres present an average diameter of $0.031 \mathrm{~mm}$ and pig-hair fibre's diameter varies between 0.07 and $0.23 \mathrm{~mm}$. Water absorption values are $12 \%, 0 \%$ and $95 \%$ for jute, micro polypropylene and pig-hair fibre, respectively. Jute fibre, tensile strength values vary from 250 to $800 \mathrm{MPa}$, the tensile strength of pig-hair fibre vary from 44.5 to $155.1 \mathrm{MPa}$ and micro polypropylene tensile strength is $310 \mathrm{MPa}[13,14,17,26,27]$.

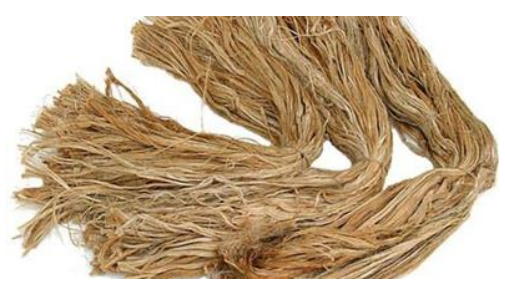

(a)

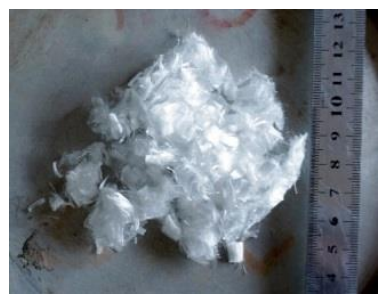

(b)

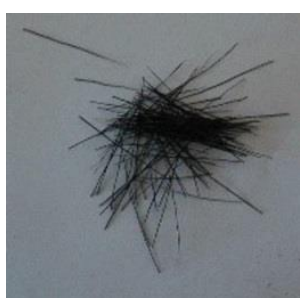

(c)

Figure 2: Sample of (a) jute fibre, (b) micro polypropylene fibre and (c) pig-hair fibre

\subsection{Specimen preparation}

To manufacture adobe blocks, the soil was oven dried for 24 hours at $110 \pm 5^{\circ} \mathrm{C}$ and let cool down at room temperature for 2 hours before mixing. All the natural fibres used for this work were oven-dried for 24 hours at $110 \pm 5{ }^{\circ} \mathrm{C}$ before mixing. Water to oven-dry soil ratio of 0.307 was used in all mixtures, compensating the water due to the absorption of jute and pig-hair fibres. The amount of fibre for each dosage is calculated as a percentage in weight of the oven-dry soil for each mixture and are indicated in Table 2. To identify the different mixtures of this study a code was implemented, were the letters V, I and A indicate if the adobe mixture corresponds to adobes with vegetal, industrial or animal fibres respectively (Table 2). The first number in the code indicates the fibre dosage (i.e. the percentage of fibres by weight of oven-dry soil) and the number after the dash in the code indicates the length of the fibre (Table 2). Micro polypropylene fibres only have a dosage number as only one length was tested. As an example, jute fibre mixture using 30mm long fibres with a dosage of fibres of $0.5 \%$ is coded as V $0.5-30$. All the adobe mixtures of this study are presented in Table 2. A total of 18 mixtures were prepared, including 15 fibre-reinforced mixes as well as three plain mixtures used for reference purposes of this study.

To ensure that no water loss occurs, a plastic film was put on the floor and on top of that the raw material was placed for the mixing process. Dry soil was mixed with fibres to homogenize the mixture. Water was poured in steps and mixed afterwards until all the water was supplied to the mixture. After mixing, the adobe mixtures were left to settle for two hours to promote uniform water absorption. Casting and compaction of the specimens were made manually to emulate traditional adobe blocks manufacturing [11]. All specimens were kept at laboratory conditions $\left(45 \%\right.$ relative humidity and $22^{\circ} \mathrm{C}$ ) for 28 days and rotated to their adjacent side in a $90^{\circ}$ angle every seven days. Only plaster specimens were kept in the same position until testing. Figure 3 presents the different specimens prepared for all the tests. 
(a)

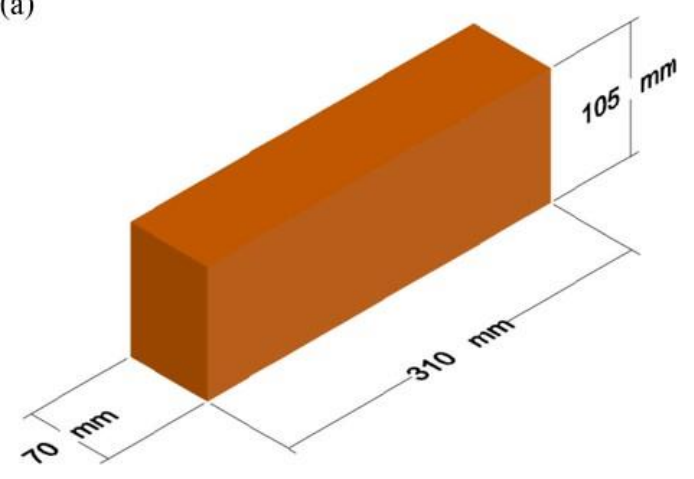

(b)

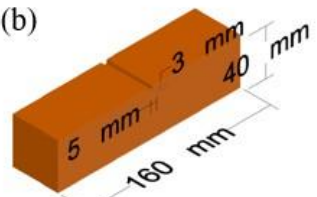

(c)

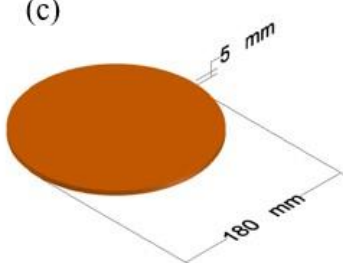

Figure 3: Specimens geometries and dimensions; (a) Beam specimen, (b) impact strength specimen and (c) plaster specimen

Table 2:Mixture proportions of adobe

\begin{tabular}{|c|c|c|c|c|}
\hline FIBRE & ID & FIBRE DOSAGE \%* & LENGTH MM & WATER/SOIL RATIO \% \\
\hline \multirow{7}{*}{ Jute } & $\mathrm{V} 0-0$ & 0 & 0 & \multirow{18}{*}{0.307} \\
\hline & V 0.5-7 & \multirow{3}{*}{0.5} & 7 & \\
\hline & V $0.5-15$ & & 15 & \\
\hline & V $0.5-30$ & & 30 & \\
\hline & V 2-7 & \multirow{3}{*}{2.0} & 7 & \\
\hline & V 2-15 & & 15 & \\
\hline & V 2-30 & & 30 & \\
\hline \multirow{4}{*}{ Micro Polypropylene } & I 0 & 0 & 0 & \\
\hline & I 0.25 & 0.25 & 12 & \\
\hline & I 0.5 & 0.5 & 12 & \\
\hline & I 1 & 1.0 & 12 & \\
\hline \multirow{7}{*}{ Pig-hair } & A $0-0$ & 0 & 0 & \\
\hline & A $0.5-7$ & \multirow{3}{*}{0.5} & 7 & \\
\hline & A $0.5-15$ & & 15 & \\
\hline & A $0.5-30$ & & 30 & \\
\hline & A $2-7$ & \multirow{3}{*}{2.0} & 7 & \\
\hline & A $2-15$ & & 15 & \\
\hline & A $2-30$ & & 30 & \\
\hline
\end{tabular}

*Percentage of the weight of fibre to the weight of oven-dry soil

\subsection{Crack width average and crack width reduction ratio}

To assess the capacity of the different fibres to control cracking due to drying shrinkage, cracks of two plaster specimens per adobe mixture were measured at seven days after casting. The measurements of the cracks were taken using a crack width comparator (for each crack width) and a calliper (for each crack length). A 20 x $20 \mathrm{~mm}$ grid was used over the plaster specimens to assist the measurement process. To evaluate the crack control developed by fibre-reinforcements, crack width average (CWA) values of each adobe mix were cal- 
culated using equation 1 .

$$
C W A_{I D x-y}=\frac{\sum l_{I D x-y}{ }^{*} w_{I D x-y}}{\sum l_{I D x-y}}
$$

where $C W A_{I D x-y}$ is the crack width average of mixture $I D x-y, l_{I D x-y}$ is the length of the cracks and $w_{I D x-y}$ is the width of the cracks of mixture $I D x-y$. Average values are calculated after measuring both specimens.

To determine the effect of the fibre on the effective crack reduction, a crack width reduction ratio $(C W R R)$ value was calculated for each fibre-reinforced mix (with respect to the plain mixes) with Equation 2.

$$
C W R R_{I D x-y}=\left(1-\frac{C W A_{I D x-y}}{C W A_{I D 0-0}}\right) \cdot 100
$$

where $C W R R_{I D x-y}$ is the percentage of reduction of cracks of adobe mixture $I D x-y, C W A_{I D x-y}$ is the crack width average of adobe mixture $I D x-y$ and $C W A_{I D 0-0}$ is the crack width average of plain adobe.

\subsection{Flexural strength}

To assess the flexural strength, a three-point bending test was implemented over beam specimens reinforced with industrial and animal fibre (Figure 3a) at an age of 28 days. Flexural strength of adobe reinforced with vegetal fibre was assessed using RILEM beam specimens (Figure 3b, 40 x 40 x $160 \mathrm{~mm}$ ). Three specimens were tested for each mixture. The span length of the test was $270 \mathrm{~mm}$, for industrial and animal mixtures, and $120 \mathrm{~mm}$ for vegetal mixtures. The testing control protocol rate was of $1 \mathrm{~mm} / \mathrm{min}$, for all mixtures. Flexural strength values were calculated using Equation 3.

$$
f_{t}=\frac{3 P L}{2 b h^{2}}
$$

where $f_{t}$ is the flexural strength of the specimen, $P$ is the maximum load registered, $L$ is the span length, $b$ is the width of the specimen and $h$ is the height of the specimen.

\subsection{Compressive strength}

Compressive strength $\left(f_{c}\right)$ of adobe reinforced with jute fibres was obtained using the halves of RILEM beam $(40 \times 40 \times 160 \mathrm{~mm})$. Cubic $(50 \times 50 \times 50 \mathrm{~mm})$ specimens were used to determine $f_{c}$ of adobe reinforced with micro polypropylene fibres. $f_{c}$ of adobe reinforced with pig-hair fibres was determined using each half obtained after the flexural strength test $(70 \times 105 \times 310 \mathrm{~mm})$. All the tests were subject to a loading rate of 0.04 $\mathrm{MPa} / \mathrm{sec}$ and a total of six specimens were tested for each adobe mixture. $f_{c}$ values were calculated using Equation 4.

$$
f_{c}=P / A
$$

where $P$ is the maximum load applied and $A$ is the contact area of the loading plate.

\subsection{Impact strength}

The impact strength test setup used in this study (Figure 4), consists of a projectile released from a specific height that impacts to the centre of a specimen, as suggested by ARAYA-LETELIER et al. [17, 28]. The values obtained from the impact strength test can be considered as an indirect measure of the material toughness $[27,29,30]$. To evaluate the impact strength, the number of blows needed to fracture the specimen was counted, calculating the fracture energy with Equation 5. Three specimens were tested for each adobe mixture.

$$
I_{e}=n \cdot m \cdot g \cdot h
$$


where $I_{e}$ is the impact energy at fracture, $n$ is the number of times the projectile was thrown, $m$ is the mass of the projectile $(0.047 \mathrm{~kg}), g$ is the gravitational constant and $h(496 \mathrm{~mm})$ is the height of the drop (Figure 4).

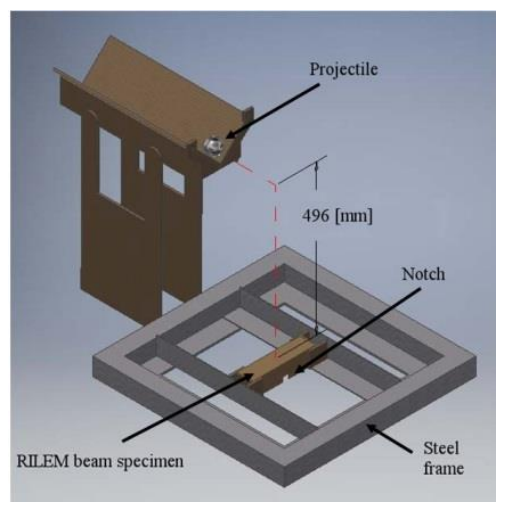

Figure 4: Impact strength test setup [17]

\section{RESULTS AND DISCUSSION}

\subsection{Crack width average and crack width reduction ratio}

Figure 5 (dark grey bars, vertical left axis) shows the CWA values of the specimens with error bars representing the minimum and maximum values obtained for mixtures with vegetal, industrial and animal fibres. CWA results ranged between 0.13 (V 2-30) to 0.93 (V 0-0) $\mathrm{mm}$ for mixtures with jute fibre, between 0.19 (I 1) to 1.09 (I 0 ) $\mathrm{mm}$ for mixtures with micro polypropylene fibres and between 0.15 (A 2-30) and 1.26 (A $0-0$ ) $\mathrm{mm}$ for mixtures with animal fibres [17, 26, 31, 32]. For comparison purposes of the cracking behaviour of different adobes with a different type of fibres, we will compare CWRR as it is a relative value to the behaviour of the unreinforced mixture of each set of samples. All adobe reinforced with natural fibres (i.e. animal or vegetal), regardless of fibre length of the, provide between 75 and $90 \%$ of CWRR at high dosages (i.e. $2 \%$ of fibres) as presented in Figure 5. The latter results showed CWRR of adobe reinforced with natural fibres match those of adobe reinforced with $1 \%$ of industrial fibres (Figure 5). No differences between CWA and CWRR were observed for adobes reinforced with different jute fibre lengths, whereas the increase of the length of pig-hair fibre enhanced CWRR values in at least 15\%. As presented in Figure 5, CWWR of adobes reinforced with industrial fibres increases nearly $16 \%$ each time fibre dosage was doubled (i.e. from 0.25 to $0.5 \%$ and from 0.5 to $1 \%$ of fibres). To achieve the same increment of CWRR as adobes with industrial fibres, the fibre dosage of adobes with natural fibres needed to increase four times (i.e. from 0.5 to $2 \%$ of fibres) (Figure 5). Specifically, for adobes reinforced with pig-hair fibre, an asymptotic response of CWRR was observed between adobes reinforced with $2 \%$ of fibre with lengths of 15 and $30 \mathrm{~mm}$ at $2 \%$. The latter could be produced due to the formation of fibre clusters in the matrix at high volumes. Further research needs to be conducted to evaluate the effect of high volumes of animal fibre on the cracking behaviour of adobe plasters. 


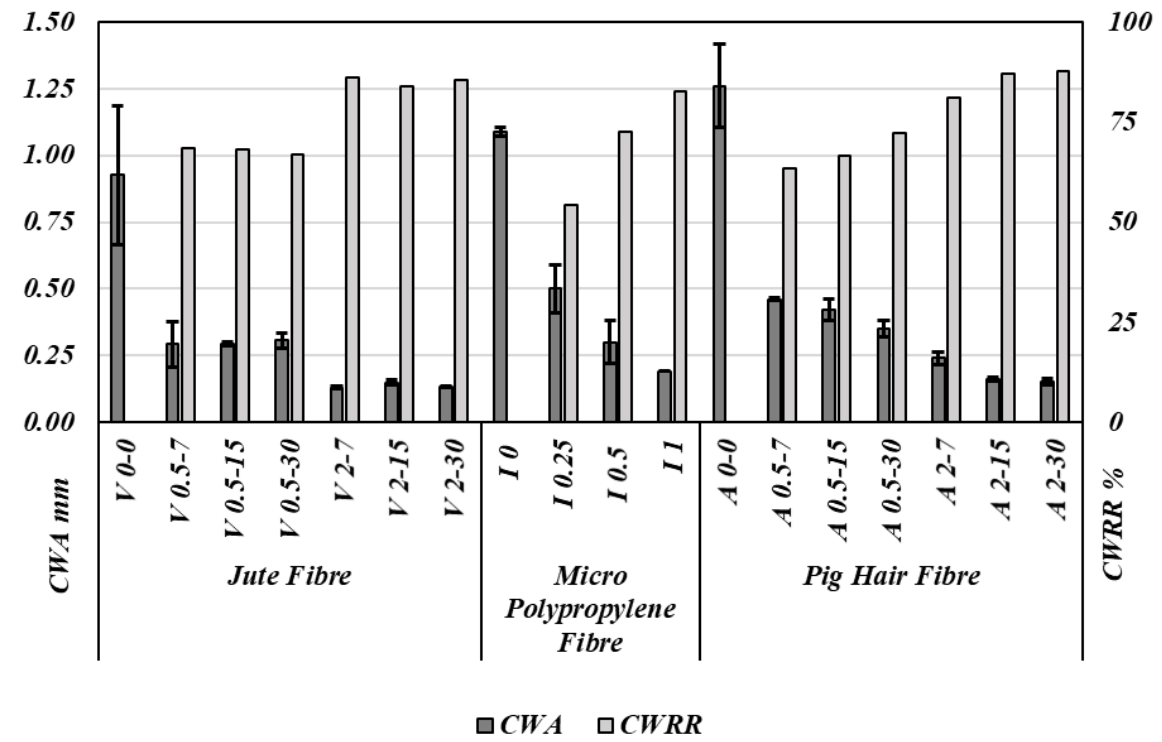

Figure 5: Crack width average (dark grey bars left vertical axis) and crack width reduction ratio (light grey bars right vertical axis) test results

\subsection{Flexural strength}

Figure 6 shows average flexural strength values (dark grey bars) and error bars (minimum and maximum values obtained) for mixtures with vegetal, industrial and animal fibres. Average flexural strength values for jute reinforced adobe blocks ranged between 0.37 (V 0-0) and 0.88 (V 2-30) MPa, between 0.51 (I 0) and 0.71 (I 1) MPa for micro polypropylene fibre and between 0.26 (A 0.5-15) and 0.41 (A 0-0) MPa for pig-hair fibre $[17,26,31]$. It is worth noticing that the average values of flexural strength of plain adobe used to compare the flexural strength of reinforced adobe with different fibres individually vary (i.e. animal fibre: [16] and industrial fibre: [24]) up to $27 \%$. According to the average and dispersion of results, flexural strength values did not increase with the addition of any fibre. Due to the number of specimens and the dispersion of results, the researchers suggest increasing the number of specimens for higher dosages of jute fibre to reduce the epistemic uncertainty of this assessment and, consequently, to statistically evaluate the significance of the fibre effect on the flexural strength. Considering the flexural strength values obtained in this work and values of fracture toughness for similar materials [33], an estimation of the length of the fracture process zone of adobe could be several orders of magnitude larger than the height of any of the samples used in this work. Therefore, changes in flexural strength related to both sizes of the samples used in this work are discarded. 


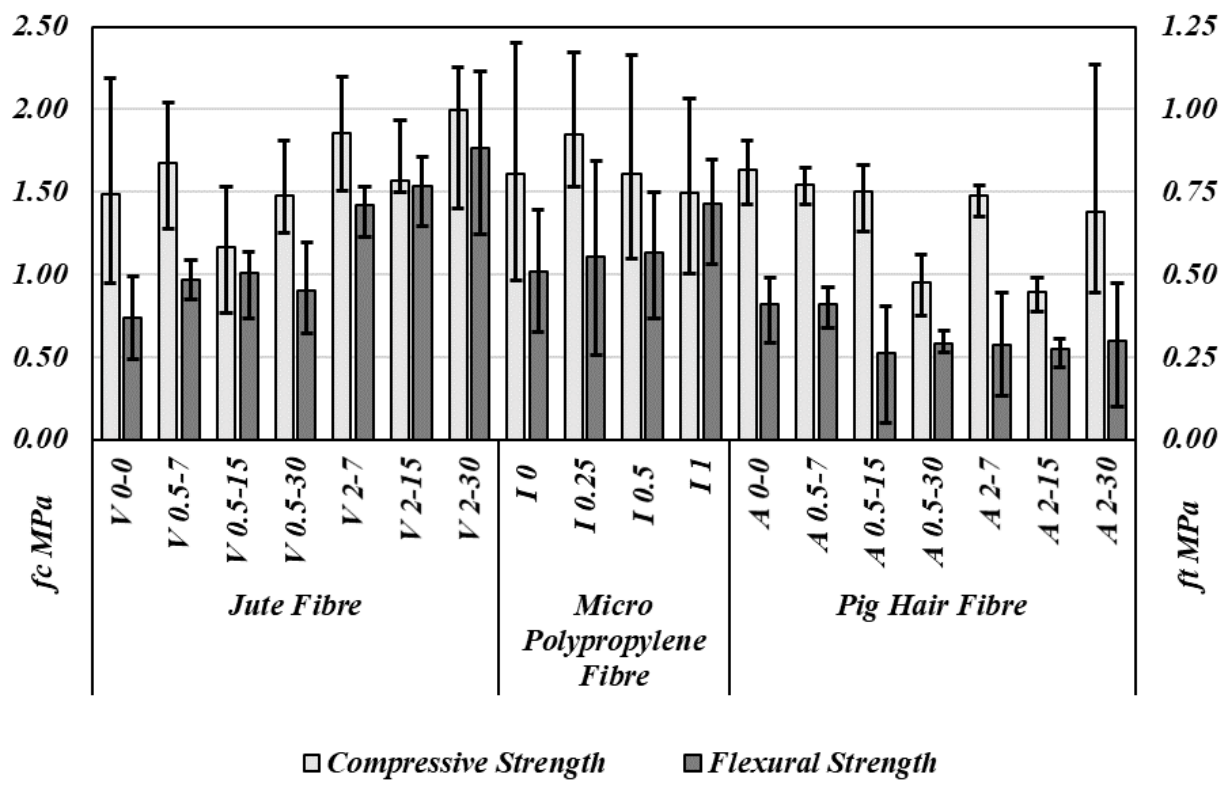

Figure 6: Compressive (light grey bars left vertical axis) and flexural (dark grey bars right vertical axis) strength test results at 28 days

\subsection{Compressive strength}

Figure 6 shows average compressive strength values (light grey bars) and error bars that represent the minimum and maximum values obtained for mixtures with vegetal, industrial and animal fibres, from 6 specimens. Average values of compressive strength of adobe reinforced with jute fibre mixtures vary from 1.49 (V 0-0) to 1.99 (V 2-30) MPa and compressive strength of adobes with animal fibre varies from 0.90 (A 2-15) to 1.64 (A 0-0) $\mathrm{MPa}$ [16]. Compressive strength values of adobes with micro polypropylene vary from 1.50 (I 1) to 1.85 (I 0.25 ) $\mathrm{MPa}$ [24]. The average values of compressive strength of plain adobe used to compare the compressive strength of reinforced adobe with different fibres individually vary (i.e. animal fibre: [16] and industrial fibre: [24]) up to $9 \%$. On the contrary, the dispersion of compressive strength of adobes was higher than $100 \%$ in some cases (Figure 6). According to the average and dispersion of the compressive strength, no increment or decrement are observed on the compressive strength of reinforced adobe blocks independent of the type, length and dosage of the fibres. These results are consistent with previous works [17]. Yet, a higher number of specimens could be evaluated in future work to reduce the epistemic uncertainty of the results and, therefore, to perform an evaluation of the statistical significance of the experimental results of this work.

\subsection{Impact strength}

Figure 7 shows average impact strength values and error bars that represent the minimum and maximum values obtained for mixtures with vegetal, industrial and animal fibres on a logarithmic scale. Jute fibre mixtures average values varied from $0.13(\mathrm{~V} 0-0)$ to 45.08 (V 2-30) $\mathrm{mJ}$, micro polypropylene fibre mixtures values ranged between 0.17 (I 0) and 13.95 (I 1) $\mathrm{mJ}$ and pig-hair fibre mixtures varied from 0.14 (A $0-0$ ) to 6.66 (A 2-30) $\mathrm{mJ}[17,26,31]$. The average values of impact strength of plain adobe used to compare the impact strength of reinforced adobe with different fibres individually vary (i.e. animal fibre: [16] and industrial fibre: [24]) up to $23 \%$. Overall, increments in fibre dosages are proportional to increments in impact strength of adobe blocks regardless of the type and length of fibres. Adobe blocks reinforced with jute fibre got the highest impact strength between natural fibres with a dosage of $2 \%$ and a length of $30 \mathrm{~mm}$ (Figure 7). Impact strength of A 2-30 reinforced adobe blocks was $2810 \mathrm{~mJ}$ higher than I 0.5, V 0.5-30 and V 27. The latter suggests that to achieve similar impact strength of adobe with industrial fibres, adobes with animal fibres require at least to double its fibre dosage compare to the earlier. Adobe blocks reinforced with pig-hair fibre had a lower impact strength compared to the mixtures reinforced with vegetal and industrial fibres. One possible explanation to the latter is the lower tensile strength of animal fibres compared to industrial fibres as evaluated by ARAYA-LETELIER et al. [34]. Adobe reinforced with industrial fibres presented similar results than adobes with vegetal fibres, specifically I 0.5 and V 0.5-30 impact strength values differed only by $10 \%$. Comparable results were obtained for industrial fibre mixtures with $0.25 \%$ dosages and vegetal mixtures with $7 \mathrm{~mm}$ fibre length and $0.5 \%$ dosage. This equivalence may be possible because the tensile 
strength of both fibres was similar.

Mixtures of jute fibre, V 0.5-30 and V 2-7, showed similar performance (3.48 and $3.95 \mathrm{~mJ}$, respectively), as well as mixtures of pig-hair fibre, A 0.5-15 and A 2-7 (1.10 and 1.03 mJ, respectively), and A 0.5-30 and A 2-15 (2.28 and $1.82 \mathrm{~mJ}$, respectively). The latter could be due to an equivalence between fibre dosage and length. A similar phenomenon was observed for cracking behaviour (Figure 5) of pig-hair fibre mixtures, where two high dosages had similar results (A 2-15 and A 2-30). Further research must be conducted to explain this effect.

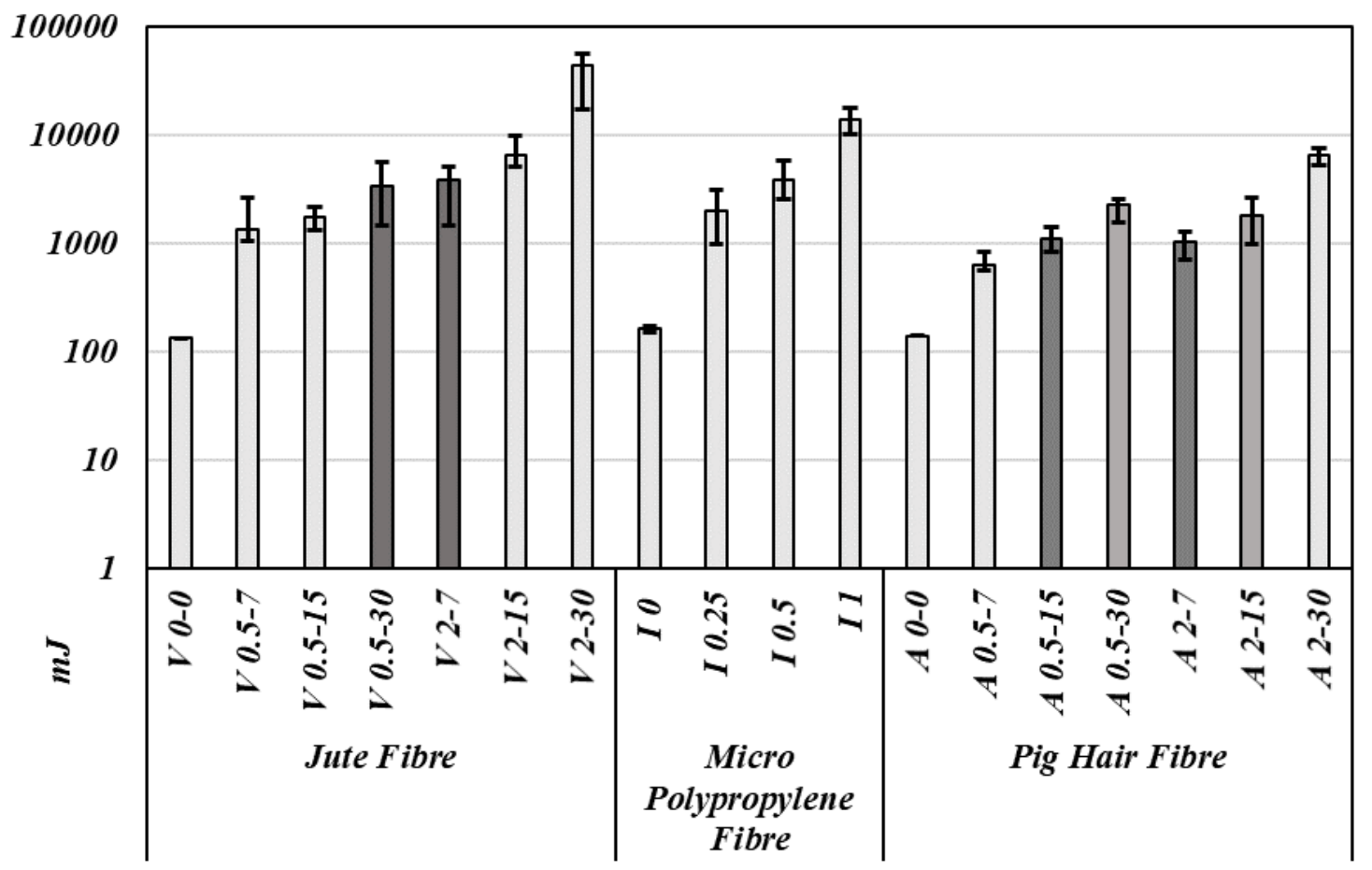

Figure 7: Average impact strength test results at 28 days

\section{CONCLUSIONS}

The following comments and conclusions can be drawn from this study:

All the fibres tested in this study reduced the cracking average widths and lengths of adobe plasters (i.e. reducing CWA and increasing CWRR at least in a 50\%). Adobes reinforced with natural fibres exhibited similar CWWR values than industrial fibres (e.g. average CWRR values were above $70 \%$ for all reinforced adobes with a fibre dosage of at least $0.5 \%$ ). Industrial fibres, design control of crack development, are more effective controlling cracking propagation of adobe plasters compared to natural fibres. Yet, similar values of CWWR of adobes reinforced with industrial fibre at $1 \%$ dosage can be achieved with higher dosages $(2 \%)$ of vegetal and animal fibres. Also, the industrial nature of micro polypropylene fibres makes them less appealing than natural fibres, because of the higher $\mathrm{CO}_{2}$ emissions generated by the manufacturing of polypropylene [30]. Animal fibre had the best performance in terms of CWWR with an average value for A 2-30 of $87 \%$. We recommend the use of jute fibre due to its performance at lower dosages (V $0.5-15)$ in contrast with animal fibre whose better performance was reached at longer lengths and higher dosages (A 215) and the industrial fibre for the mentioned reasons.

Impact strength of all mixtures was increased by the addition of fibre. Specifically, adobes reinforced with jute fibre $2.0 \%$ dosage and $30 \mathrm{~mm}$ length, had the best performance, increasing the impact strength of adobe blocks in 2 orders of magnitude in comparison with plain adobe.

Compressive and flexural strength values were not influenced by the addition of fibres; however, the variability of the results was increased in comparison to plain adobe. If two standard deviation error bars are considered ( $95 \%$ of confidence), flexural strength values did not statistically increase neither decrease as the 
fibre dosage or length were increased, for all types of fibre. Further research addressing the formation of clusters inside the mixture could explain the higher variability of the results as more fibre is added to the mixture.

\section{ACKNOWLEDGEMENTS}

The authors would like to thank Arnaldo Puebla, Andrés Glade and Wladimir Vergara for their help on the experimental campaign.

\section{BIBLIOGRAPHY}

[1] CHENG, L., et al., "2018 Continues Record Global Ocean Warming,” Adv. Atmos. Sci., v. 36, n. 3, pp. 249-252, 2019.

[2] HAMLINGTON, B.D., FASULLO, J.T., NEREM, R.S., et al., "Uncovering the Pattern of Forced Sea Level Rise in the Satellite Altimeter Record," Geophys. Res. Lett., v. 46, n. 9, pp. 4844-4853, 2019.

[3] HUANG, L., KRIGSVOLL, G., JOHANSEN, F., et al., "Carbon emission of global construction sector," Renew. Sustain. Energy Rev., v. 81, n. June, pp. 1906-1916, 2018.

[4] KOCH, G., KUNZE, C., SEIDL, J., "Loam Construction - From a Niche Product to an Industrial Building System,” 2005 World Sustain. Build. Conf. Tokyo, 27-29 Sept. 2005, v. 2005, n. September, pp. 27-29, 2005.

[5] UNITED NATIONS, "UN projects world population to reach 8.5 billion by 2030 , driven by growth in developing countries,” 2015. [Online]. Available:

https://www.un.org/sustainabledevelopment/blog/2015/07/un-projects-world-population-to-reach-8-5-billionby-2030-driven-by-growth-in-developing-countries/.

[6] CATALDO-BORN, M., ARAYA-LETELIER, G., PABÓN, C., "Obstacles and Motivations for Earthbag Social Housing in Chile : Energy, Environment, Economic and Codes Implications," Rev. la Construcción. J. Constr., v. 15, n. 3, pp. 17-26, 2016.

[7] NIROUMAND, H., ZAIN, M.F.M., JAMIL, M., et al., "Earth Architecture from Ancient until Today," Procedia - Soc. Behav. Sci., v. 89, pp. 222-225, 2013.

[8] STEEN, A.S., STEEN, B., KOMATSU, E., Built by hand: vernacular buildings around the world. Gibbs Smith, 2003.

[9] MINKE, G., Building with Earth. 2006.

[10] MINKE, G., Building with Earth: Design and Technology of a Sustainable Architecture. Walter de Gruyter, 2009.

[11] MINKE, G., Earth construction handbook: the building material earth in modern architecture. Southampton: WIT Press, 2000.

[12] LABOREL-PRENERON, A., AUBERT, J.E., MAGNIOT, C., et al., "Plant aggregates and fibers in earth construction materials: A review," Constr. Build. Mater., v. 111, pp. 719-734, 2016.

[13] BORDOLOI, S., KASHYAP, V., GARG, A., et al., "Measurement of mechanical characteristics of fiber from a novel invasive weed: A comprehensive comparison with fibers from agricultural crops," Meas. J. Int. Meas. Confed., v. 113, n. August 2017, pp. 62-70, 2018.

[14] SEN, T., REDDY, H.N.J., "Application of Sisal , Bamboo , Coir and Jute Natural Composites in Structural Upgradation,” Int. J. Innov. Maagement Technol., v. 2, n. 3, pp. 186-191, 2011.

[15] BINICI, H., AKSOGAN, O., SHAH, T., "Investigation of fibre reinforced mud brick as a building material," Constr. Build. Mater., v. 19, n. 4, pp. 313-318, 2005.

[16] ARAYA-LETELIER, G., GONZALEZ-CALDERON, H., KUNZE, S., et al., "Waste-based natural fiber reinforcement of adobe mixtures: physical, mechanical, damage and durability performance assessment (Accepted for publication)," J. Clean. Prod., 2020.

[17] ARAYA-LETELIER, G., CONCHA-RIEDEL, J., ANTICO, F.C., et al., "Influence of natural fiber dosage and length on adobe mixes damage-mechanical behavior," Constr. Build. Mater., v. 174, pp. 645-655, Jun. 2018.

[18] AYMERICH, F., FENU, L., MELONI, P., "Effect of reinforcing wool fibres on fracture and energy absorption properties of an earthen material," Constr. Build. Mater., v. 27, n. 1, pp. 66-72, 2012.

[19] ASTM INTERNATIONAL, “ASTM D7928 - 17 Standard Test Method for Particle-Size Distribution 
(Gradation) of Fine-Grained Soils Using the Sedimentation (Hydrometer) Analysis.” p. 25, 2017.

[20] ASTM INTERNATIONAL, “ASTM D4318 - 17 Standard Test Methods for Liquid Limit, Plastic Limit, and Plasticity Index of Soils.” p. 20, 2017.

[21] VILLAMIZAR, M.C.N., ARAQUE, V.S., REYES, C.A.R., et al., "Effect of the addition of coal-ash and cassava peels on the engineering properties of compressed earth blocks," Constr. Build. Mater., v. 36, pp. 276-286, 2012.

[22] DUARTE, I., PEDRO, E., VARUM, H., et al., "Soil mineralogical composition effects on the durability of adobe blocks from the Huambo region, Angola," Bull. Eng. Geol. Environ., v. 76, n. 1, pp. 125-132, 2017.

[23] SANTOS, L.M.A., NETO, J.A.D.S., DE AZERÊDO, "Soil characterization for adobe mixtures containing Portland cement as stabilizer," Rev. Mater., v. 25, n. 1, 2020.

[24] FABBRI, A., SOUDANI, L., MCGREGOR, F., et al., "Analysis of the water absorption test to assess the intrinsic permeability of earthen materials," Constr. Build. Mater., vol. 199, no. December, pp. 154-162, 2019.

[25] HOWARD, A.K., Soil classification handbook: unified soil classification system. Second edition. Denver, Colo. : Geotechnical Branch, Division of Research and Laboratory Services, Engineering and Research Center, Bureau of Reclamation, 1986., 1986.

[26] ARAYA-LETELIER, G., CONCHA-RIEDEL, J., ANTICO, F.C., et al., "Experimental mechanicaldamage assessment of earthen mixes reinforced with micro polypropylene fibers," Constr. Build. Mater., v. 198, pp. 762-776, Feb. 2019.

[27] ACI COMMITTEE 544 et al., "State of the Art Report on Fiber Reinforced Concrete Reported by ACI Committee 544," ACI Struct. J., vol. 96, no. Reapproved, 2002.

[28] ARAYA-LETELIER, G., ANTICO, F.C., PARRA, P., et al., "Fiber-Reinforced Mortar Incorporating Pig Hair," Adv. Eng. Forum, v. 21, pp. 219-225, 2017.

[29] MINISTERIO DE VIVIENDA Y URBANISMO, "Manual de Pavimentación y Aguas Lluvia de Serviu Metropolitano Chile," 2019.

[30] ARAYA-LETELIER, G., MATURANA, P. CARRASCO, M., et al. "Mechanical-damage behavior of mortars reinforced with recycled polypropylene fibers," Sustain., v. 11, n. 8, 2019.

[31] CONCHA-RIEDEL, J., ARAYA-LETELIER, G., ANTICO, F.C., et al., "Influence of Jute Fibers to Improve Flexural Toughness, Impact Resistance and Drying Shrinkage Cracking in Adobe Mixes," pp. 269$278,2019$.

[32] ARAYA-LETELIER, G., ANTICO, F.C., CONCHA-RIEDEL, J., et al. "Effectiveness of Polypropylene Fibers on Impact and Shrinkage Cracking Behavior of Adobe Mixes," in Earthen Dwellings and Structures Effectiveness, B. V. V. Reddy, M. Mani, and P. Walker, Eds. Springer Singapore, 2019.

[33] MUSTAPHA, K., ANNAN, E., AZEKO, S.T., et al. "Strength and fracture toughness of earth-based natural fiber-reinforced composites,” J. Compos. Mater., v. 50, n. 9, pp. 1145-1160, 2016.

[34] ARAYA-LETELIER, G., ANTICO, F.C., CARRASCO, M., et al., "Effectiveness of New Natural Fibers on Damage-Mechanical Performance of Mortar,” Constr. Build. Mater., v. 152, pp. 672-682, 2017.

\section{ORCID}

José Concha-Riedel Federico Carlos Antico Gerardo Araya-Letelier https://orcid.org/0000-0002-0038-1865

https://orcid.org/0000-0001-7828-9391

https://orcid.org/0000-0003-4252-1341 